\title{
LAPAROSCOPIC CHOLECYSTECTOMY FOR GALL STONE DISEASE. A SINGLE CENTER EXPERIENCE.
}

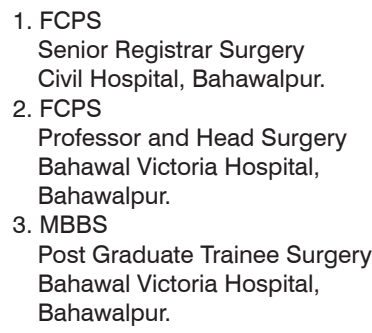

Correspondence Address: Dr. Shehzad Ahmad Qamar Department of Surgery

Civil Hospital, Bahawalpur. shehzadqamar147@gmail.com

Article received on:

$17 / 09 / 2018$

Accepted for publication: $31 / 08 / 2019$

\begin{abstract}
Shehzad Ahmad Qamar', Munawar Jamil², Kokab Salim ${ }^{3}$
ABSTRACT... Objectives: Laparoscopic cholecystectomy has turned into the gold standard for patients with symptomatic cholelithiasis. But still this procedure is not complication free. Many a time's laparoscopic cholecystectomy needs to be converted to open cholecystectomy. Study Design: Observational study. Setting: Civil Hospital Bahawalpur. Period: 3 years from July 2015 to June 2018. Material \& Methods: Carried out to review the frequency of complications encountered in laparoscopic cholecystectomy by assessing 400 cases of laparoscopic cholecystectomies. Performa was intended to incorporate important demographic data, history of illness, examination and investigations. Results: The major complication of our procedure was bleeding. Bleeding from the trocar site happened in 11 cases $(2.75 \%)$, vascular damage in the callots triangle in $2(0.5 \%)$ and from liver bed in $19(4.75 \%)$ cases, followed by biliary leak that happened in $20(5 \%)$ cases. Spilled gallstones were seen in 8(2\%), Port site infection in $24(6 \%)$ cases. Common bile channel stricture was accounted for in 5 patients, 14 (3.5\%) out of 400 patients were converted to open surgery. Mortality was low for our situation I.e. 1 patient. Conclusion: Laparoscopic cholecystectomy is becoming a safe procedure in terms of complications.
\end{abstract}

Key words: Cholecystectomy, Gallstones, Laparoscopic.

Article Citation: Qamar SA, Jamil M, Salim K. Laparoscopic cholecystectomy for gall stone disease. A single center experience. Professional Med J 2020; 27(9):19831988. DOI: 10.29309/TPMJ/2020.27.09.5969

\section{INTRODUCTION}

Laparoscopic cholecystectomy has turned into the gold standard for patients with symptomatic cholelithiasis. The advantages of laparoscopic cholecystectomy over conventional open cholecystectomy as far as restricted postoperative agony, shorter hospitalization, earlier resumption of movement, and enhanced cosmoses have been promptly clear ${ }^{1}$ Laparoscopic cholecystectomy is a broadly acknowledged choice for chronic cholecystitis while it is viewed as a relative contraindication for acute cholecystitisbecause of its substantially more post operative complications especially increased frequency of common bile duct injuries. ${ }^{2}$ Laparoscopic cholecystectomy is obviously the treatment of choice for symptomatic cholelithiasis.

The conspicuous and implied points of interest of laparoscopic cholecystectomy made it appealing to patients, specialists, and doctors (e.g., less scarring, abbreviated hospital stays, early come back to routine work). ${ }^{3}$

The complexities experienced during Laparoscopic cholecystectomy are various: some that are particular to this special strategy and some that are regular to laparoscopic surgery all in all. These incorporate problems identified with anesthesia, problems identified with peritoneal access (e.g., vascular and visceral injuries, and port-site hernia development); complexities identified with pneumoperitoneum (e.g., cardiovascular inconvenience, pneumonic intricacies, and gas embolism) and difficulties identified with thermo coagulation. Particular inconveniences of Laparoscopic cholecystectomy are hemorrhage, gall bladder rupture, bile spillage, bile conduit damage, and per hepatic collection), and others, for example, extra biliary fistula, wound sepsis, hematoma, foreign body considerations, metastatic port-site deposits, and 
cholelithoptysis. ${ }^{1,4}$ Some of these complications and a few different components can require the change from Laparoscopic cholecystectomy to open cholecystectomy.

After some time the rate of difficulties related with laparoscopic cholecystectomy have declined and an apparent increment in number of laparoscopic cholecystectomies being done.

The aim of this study is to consider the complications encountered during and after laparoscopic complications in gall bladder diseases both symptomatic and asymptomatic. Also to high-light the risk factors that may redeem Iparoscopic cholecystectomy to open cholecystectomy.

\section{MATERIAL \& METHODS}

A total of 400 patients were recruited in this observational-pilot study by non-probability purposive sampling. All patients were recruited over the period of three years starting from April, 2016 till March 2019.Patients were admitted from outpatient department after written informed consent. All patients with symptomatic gall stone disease undergoing laparoscopic cholecystectomy were included in the study. Patient with choledocholithiasis, carcinoma gall bladder, significant bleeding disorders, chronic liver disease and associated cardiac or respiratory co-morbidities were excluded from the study. Demographic variables were recorded. All procedures were done by same team of consultants.

\section{Operative Procedure}

All procedures were performed under general anesthesia. Pnemoperitoneum set up by either closed or open technique. Extra working port inserted in right sub costal area. Patient put in reverse trendelenberg position slightly tilted to left. Neck of gallbladder is withdrawn towards right iliac fossa exposing calot's triangle. Cystic duct and the cystic artery are clearly defined. Once the anatomy is unmistakably characterized and triangle of calot has been exposed wide open, the cystic duct and cystic artery are ligated and cut. Sharp dissection is then done to separate the gall bladder from gallbladder bed. Once free gall bladder is removed through umbilicus. Ports are withdrawn under direct vision to assess for potential bleeding or injury. Samples are then sent to pathology department in $10 \%$ formalin for histopathological evaluation. Clinical diagnosis is affirmed by subjecting all samples to detailed histopathological examination. All complications were recorded on specially designed proforma. Qualitativevariables like genderand complications were calculated and presented as frequency and proportions. Quantitative variables like age were presented as mean and standard deviation.

\section{RESULTS}

A sum of 400 patients had laparoscopic cholecystectomy during the study time frame. The patients of age ranged 21-40 years were in the majority $(52.5 \%)$ of cases Table-l. A total of $37.5 \%$ were in $41-60$ year age group while 25 patients were under 20 years and 15 were over 60 years as shown in Table-Il. Most of the patients were females. Table-III shows that the major complication of our procedure was bleeding. Bleeding from the trocar site happened in 11 cases (2.75\%), vascular damage in the calot's triangle in $2(0.5 \%)$ and from liver bed in $19(4.75 \%)$ cases. The second most common complication was biliary leak and happened in $20(5 \%)$ cases. In 17 cases it ceased on its own on fourth post operation day and 3 patients required intervention with $T$ - Tube and Roux-en$Y$ hepaticojejunostomy. Spilled gallstones were seen in $8(2 \%)$ situations where every one of them were recuperated during the procedure. Port site infection in $24(6 \%)$ cases which was high when contrasted with the available data. Common bile channel stricture was accounted for in 5 patients that was $1.25 \%$ of the aggregate patients and discovered later on during follow up. Gut damage and port site hernia happened in none in our study. $14(3.5 \%)$ out of 400 patients were changed over to open surgery because of adherent gall bladder in 6 cases, 6 because of altered anatomy and 2 because of bleeding during the procedure which was not controlled with regular manoeuvres. 
Mortality was low for our situation I.e. 1 patient who was a high risk female for both surgery and anesthesia. 291 patients followed up following 2 weeks and 109 patients were lost to follow up.

\begin{tabular}{|l|c|c|}
\hline Pre OP Diagnosis & $\begin{array}{c}\text { Number } \\
\text { of Cases }\end{array}$ & $\begin{array}{c}\text { Percentage } \\
\%\end{array}$ \\
\hline Acute calculus cholecystitis & 40 & 10 \\
\hline Chronic calculus cholecystitis & 328 & 82 \\
\hline Acalculuscholecystitis & 20 & 5 \\
\hline Gallbladder polyp & 8 & 2 \\
\hline Empyema & 4 & 1 \\
\hline
\end{tabular}

Table-I. Operative diagnosis.

\begin{tabular}{|l|c|c|}
\hline Characteristics & $\begin{array}{c}\text { Number of } \\
\text { Patients }\end{array}$ & Percentage \% \\
\hline AGE: $<20$ & 25 & 6.25 \\
\hline $21-40$ & 210 & 52.5 \\
\hline $41-60$ & 150 & 37.5 \\
\hline$>60$ & 15 & 3.75 \\
\hline SEX & & \\
\hline Male & 36 & 9 \\
\hline Female & 364 & 91 \\
\hline
\end{tabular}

Table-Il. Age and gender distribution

\begin{tabular}{|l|c|c|}
\hline \multicolumn{1}{|c|}{ Complications } & $\begin{array}{c}\text { Number of } \\
\text { Patients }\end{array}$ & Percentage \% \\
\hline Bleeding trocar site & 11 & 2.75 \\
\hline Vascular injury & 2 & 0.5 \\
\hline Liver bed bleeding & 19 & 4.75 \\
\hline Spilled gall stones & 8 & 2 \\
\hline Biliary leak & 20 & 5 \\
\hline Injury to the CBD & 5 & 1.25 \\
\hline Bowel injury & 0 & 0 \\
\hline Port site infection & 24 & 6 \\
\hline Port hernia & 0 & 0 \\
\hline $\begin{array}{l}\text { Conversion to open } \\
\text { surgery }\end{array}$ & 14 & 3.5 \\
\hline Mortality & 1 & 0.25 \\
\hline Total & 122 & 30.5 \\
\hline \multicolumn{1}{|c|}{ Table-III. Complications of laparoscopic } \\
cholecystectomy
\end{tabular}

\section{DISCUSSION}

For chronic cholecystitis and symptomatic cholelithiasis, laproscopic cholecystectomy has taken over Open cholecystectomy and is considered as the best quality level. ${ }^{5,6}$ in almost all major cities and tertiary level hospital in our country laparoscopic cholecystectomy is presently being performed. The laparoscopic approach where brings various favourable circumstances, it is related with higher complication rate particularly in teaching facilities. ${ }^{5}$ probably due to a steep learning curve ${ }^{1}$ This investigation was primarily meant to concentrate on the complications of Laparoscopic cholecystectomy. In our study dominant part $(52.5 \%)$ of the patients were in the age bracket 21-40 years while $25(6.25 \%)$ were under 20 years old fundamentally youngsters with haemolytic anemia alluded by pediatrician for elective cholecystectomy. 91\% were females. Female to male proportion is $4.5: 1$ with mean age was 43.7 years in an investigation of laproscopic cholecystectomy in intense cholecystitis. ${ }^{6}$

Weutilized thethree portapproachforlaparoscopic cholecystectomy in most of our cases while established 4-port approach was additionally utilized as a part of the staying troublesome cases. However certain newer techniques using only two port needlescopic cholecystectomy utilizing $3 \mathrm{~mm}$ miniaturized instrument is in practice in certain advanced centres further improving the surgical results concerning pain and cosmoses. ${ }^{7}$ In our cases we utilized the veress needle for making pneumoperitoneum, while in one of the studies on laparoscopic cholecystectomy, direct trocar insertion without pneumoperitoneum was appeared to be safe, effective, quick and simple alternative method, diminishing the complication rate related to laparoscopic cholecystectomy. ${ }^{8}$ Frequency of wounds from veress needle or trocars is reported to be around $0.2 \% .{ }^{9}$ Bleeding during the procedure was the commonest problem encountered during the procedure. Bleeding from the trocar site happened in 11 cases $(2.75 \%)$ of these 9 were controlled with pressure alone and just 2 required port site exploration and ligation of the vessels, vascular damage in the callots triangle during dissection happened in $2(0.5 \%)$ and both were changed over to open surgery because of inability to control bleeding by clip application and from liver bed in 19 (4.75\%) cases. Liver bed bleed was controlled with diathermy while drain was placed in few cases because of little ooze. in a meta- analysis by Shea, 163 patients 
out of 15,596 endured vascular damage required conversion to open surgery with a rate of $8 \%$ however the rate of bleeding complications from the liver is very little. ${ }^{4}$ Morbidity is increased by concomitant vascular injuries during laproscopic cholecystectomy. ${ }^{10}$

Bile conduit damage is an extreme and dangerous complexity of Laparoscopic cholecystectomy and as per different analyses frequency of bile duct injuries is appeared to be $0.5 \%$ to $1.4 \%$. Bile duct injury is although occasional yet dangerous complication of laparoscopic cholecystectomy and can be minimized by utilizing locking clips rather than simple clips. ${ }^{10}$ In our study bile duct injury was least and biliary leak happened in just $20(5 \%)$ cases. In 17 cases the leak halted after the fourth day of operation with no intervention required while in 3 instances of common bile duct (CBD) damage, $\mathrm{T}$ tube was put after ERCP in 2 cases while in the other laparotomy with Roux-en$Y$ hepaticojejunostomy was selected.

Spillage of gallstones into the peritoneal cavity during Laparoscopic cholecystectomy is commonly due to gallbladder rupture and might be related with serious complications, and every effort ought to be made to retrieve spilled gallstones yet conversion is not mandatory. ${ }^{11}$ In our study gallstone spillage occurred in $8(2 \%)$ cases and maximum number were retrieved during the procedure, and no postoperative complications due to spilled gallstones was recorded. $6 \%$ i.e., 24 patients had port site infection that was high as compared to the data available, and was treated with antibiotics daily dressings and debridements. One of the major benefits laparoscopic approach renders is significant reduction in the postoperative infection. In open surgery the rates of surgical infection is $8 \%$ versus $2 \%$ seen in laparoscopic surgery. However in another study it is $1.4 \%$ in laproscopic surgeries versus $14.8 \%$ in open cases is reported.

Reported incidence in certain studies about bowel injury during laparoscopic cholecystectomy is $0.07-0.7 \%$ and most probably happens at the trocar insertion, seldom during dissection and adhesiolysis and that they often remain unobserved during operation. ${ }^{4}$ In our study there was no case of bowel injury. This was because vigilant measures were adopted to prevent bowel injury l.e. trocar insertion under vision and inspection of abdomen before retreating endoscope.

14 (3.5\%) out of 400 patients were changed over to open surgery because of adherent gall bladder in 6 cases, 6 because of altered anatomy and 2 because of bleeding during the procedure which was not controlled with regular maneuvers. signs of inflammation seen on ultrasound and age above sixty years were the identified risk factors for conversion as studied by. Tayab $\mathrm{M}$ et al, in their study. ${ }^{12} 10$ out of these patients were males who needed conversion from lap-chole to open chole. many studies have supported the idea that male gender is a risk factor for converting laproscopic cholecystectomy to open cholecystectomy because of disease severity that is seen more in men than women both in acute as well as chronic cholecystitis. another reason being that men seek less medical attentetion and that too later than the women because of a greater threshold. ${ }^{13}$ contrary to it many studies declined this idea and found no statistical difference depending upon the gender.

In our study male gender was a significant factor that caused conversion from laparascoic cholecystectomy to open cholecystectomy.

Al Salamah, has reported disturbed anatomy in the region of callot's triangle as the commonest reason for conversion observed in $41.5 \%$ of converted cases while male gender, age over 65 years, high leukocytes count, gallbladder wall thickness over $4 \mathrm{~mm}$ on USG were observed as the most significant determinants for conversion to open procedure. ${ }^{6}$

A conversion rate of $1.88 \%$ has been reported in a series of 1220 patients from a single center. ${ }^{14}$ Raised TLC levels and raised ALP levels have been studied to be the cause of difficult surgery and thus reasons for converting laparoscopic cholecystectomy to open cholecystectomy. Raised TLC shows acute inflammation and edema of the gall bladder making the surgery less easy. 
Rattner et al in their study concluded association of raised Alkaline phosphatase (ALP) and difficult delivery and thus need of converting laparoscopic cholecystectomy to open cholecystectomy. such association was also studied in other centres that showed raised ALP reflects more inflammation and thus labelling it as a signification risk factor for conversion. ${ }^{13,15,16-19}$

Bile duct injury during laparoscopic cholecystectomy is highly anticipated and feared complication and may result in biliary strictures afterfew months of laparoscopic cholecystectomy, increasing the morbidity and mortality associated with the procedure. ${ }^{19}$ These strictures are usually the results of biliary reconstruction for injuries after cholecystectomy or excessive use of electrocautery close to CBD. ${ }^{20}$ CBD stricture occurred in $5(1.42 \%)$ of our cases. ERCP was done in these cases, in 2 cases surgical repair with Roux-en-Y Hepaticojejunostomy was done with good results. 3 cases were lost to follow up, probably visited higher center for treatment.

Mortality was luckily low in our series with just one case $(0.25 \%)$. female high risk patient with multiple organ disease, developed cardiac arrest and expired on the first postoperative day in the intensive care unit. Others have reported a morbidity of $2.9 \%$ with no mortality. ${ }^{6}$

Average hospital stay was two days in our study while it has been reported as 2.29 days including the prolonged stay in complicated cases in a study from one center by VagenasK et al. ${ }^{14}$ In spite of the above mentioned complications the overall outcome was satisfactory, with higher patient acceptance of the procedure.

\section{CONCLUSION}

Laparoscopic cholecystectomy is the most frequently performed laparoscopic procedure. It has replaced open cholecystectomy in several centers attributable to its high safety index and low morbidity and mortality rates related to it. All patients presenting with cholelithiasis and cholecystitislaproscopic cholecystectomy is safe and effective. Most of the complications are due to lack of expertise or knowledge of a typical error.
Proper patient selection, proper pre operative work up, anticipating the possible complication, a low threshold for conversion and adequate training facilitate to decrease the frequency of complications encountered during and after laparoscopic cholecystectomy.

Copyright@ 31 Aug, 2019.

\section{REFERENCES}

1. Daniel DJ, Millikan KW, Economou SG, Doolas A, Ko ST, Airan MC. Complications of Laparoscopic Cholecystectomy: A National Survey of 4,292 Hospitals and an Analysis of 77,604 Cases. Am J Surg 1993; 165: 9-14.

2. Giger UF, Michel JM, Thlnderbitzin D, Kocher T, Krahenbuhl L, et al. Risk factors for perioperative complications in patients undergoing laparoscopic cholecystectomy: Analysis of $\mathbf{2 2 . 9 5 3}$ consecutive cases from the Swiss Association of Laparoscopic and Thoracoscopic Surgery Database. J Am CollSurg 2006; 203: 723-8.

3. Shea JA, Healey MJ, Berlin JA, Clarke JR, Malet PF, Staroscik RN, et al. Mortality and complications associated with laparoscopic cholecystectomy a meta-analysis. Ann Surg 1996; 224: 609-20.

4. Lee VS, Chari RS, Cucchiaro G, Meyers WC. Complications of laparoscopic cholecystectomy. Am J Surg 1993; 165:527-32.

5. Cawich SO, Mitchell DI, Newnham MS, Arthurs M. A comparison of open and laparoscopic cholecystectomy done by a surgeon in training. West Indian Med J 2006; 55(2): 103-9.

6. Al-Salamah SM. Outcome of laparoscopic cholecystectomy in acute cholecystitis. J Coll Physicians Surg Pak 2005; 15(7): 400-3.

7. Lee KW, Poon CM, Leung KF, Lee DW, Ko CW. Two Port needlescopic cholecystectomy: Prospective study of 100 cases. Hong Kong Med J 2005; 11(1); 30-5.

8. Prieto Diazchavez E, Median Chavez J, L Gonzalez Ojeda $A$, et al. Direct trocar insertion without pneumoperitoneum and the veress needle in laparoscopic cholecystectomy: A comparative study. Acta Chir Belg 2006; 106(5).

9. Shamiyeh A, Wanyand W. Laparoscopic cholecystectomy: Early and late complication and their treatment, Langenbecks arch Surg 2004; 389: 164-17. 
10. Frilling A, Li J, Weber F, Fruhaus NR, et al. Major bile duct injuries after laparoscopic cholecystectomy: A tertiary center experience. J GastrointestSurg 2004; 8(6): 679-85.

11. Zehetner J, Shamiyeh A, Wayand W. Lost gallstones in laparoscopic cholecystectomy: All possible complications. Am J Surg 2007; 193 (1): 73-8.

12. Tayab M, Raza SA, Khan MR, Azami R. Conversion from laparoscopic to open cholecystectomy: Multivariate analysis of preoperative risk factors. J Postgrad Med 2005; 51(1):17-20.

13. Satish KB, Umesh KC, Gopal G, Yudhir S, Anuj $D$. Evaluation of risk factors in conversion of laparoscopic cholecystectomy in cases of acute cholecystitis. Int J of cont. med. Research. 2015; 2(2); 205-09.

14. Vagenas K, Karacanakos SN, Spyropoulos C, et al. Pararoscopic cholecystectomy: A report from a single center. World J Gastroenterol 2006; 12(24): 3887-90.

15. Rishi Kant Aryal, Rakchhya Gautam. Retrospective assessment of laproscopic cholecystectomy versus open cholecystectomy in geriatric patients with acute cholecystitis: A comparative study. International Journal of Contemporary Medical Research 2017; 4(1):295-297.
16. Hardeep Singh Gill, Ashit Gupta, Bir Singh. Evaluation of the role of various factors in conversion of laparoscopic cholecystectomy into open cholecystectomy. International Journal of Contemporary Medical Research 2016; 3(10):30313035.

17. Ayanat Husain, Saurabh Pathak, Huma Firdaus. Assessment of operative predictors for difficulty in laproscopic cholecystectomy. International Journal of Contemporary Medical Research 2016; 3(4):1232-1234.

18. andeep Singh, Karnail Singh, Inderjit Singh Chawla. Laparoscopic cholecystectomy with and without drainage - a comparative clinical study. International Journal of Contemporary Medical Research 2017; 4 (1):117-120.

19. Sikora SS, Pottakkar B, Srikanth, et al. Postcholecystectomy benign biliary strictures-longterm results. Dig Surg 2006; 23(56):304-12.

20. Hochstader $H$, BekavacBeslin $M$, Doko $M$, et al. Functional Liver damage during laparoscopic cholecystectomy as the sign of the late common bile duct structure development. Hepato Gastroenterology 2003; 50:676-9.

\begin{tabular}{|c|c|c|c|}
\hline \multicolumn{4}{|c|}{ AUTHORSHIP AND CONTRIBUTION DECLARATION } \\
\hline Sr. \# & Author(s) Full Name & Contribution to the paper & Author(s) Signature \\
\hline 1 & Shehzad Ahmad Qamar & $\begin{array}{l}\text { Writing the manuscript, } \\
\text { Concept planning. }\end{array}$ & ohenzad. \\
\hline 2 & Munawar Jamil & $\begin{array}{l}\text { Supervision, Analysis review } \\
\text { of literature. }\end{array}$ & \\
\hline 3 & Kokab Salim & $\begin{array}{l}\text { Data collection, Study } \\
\text { design and references. }\end{array}$ & \\
\hline
\end{tabular}

